\title{
Sexo e Sexualidade: O que adolescentes do Ensino Fundamental têm a dizer?
}

\author{
Sex and Sexuality: What do elementary school teenagers have to say?
}

\author{
J. S. Lima ${ }^{*} ;$ M. F. Landim² \\ ${ }^{1}$ Instituto Federal de Sergipe, Campus Glória, 49680-000, Nossa Senhora da Glória-SE, Brasil \\ ${ }^{2}$ Departamento de Biologia, Universidade Federal de Sergipe, 49100-000, São Cristóvão-SE, Brasil \\ *juliano.lima@ifs.edu.br \\ (Recebido em 26 de outubro de 2020; aceito em 19 de fevereiro de 2021)
}

\begin{abstract}
A sexualidade na adolescência foi abordada durante muito tempo apenas sob o aspecto biológico e reprodutivo. Na atualidade, porém, não podemos ignorar a expressão dos diferentes gêneros na formação da identidade e no comportamento individual. O objetivo desse estudo é identificar ideias e valores, explícitos e implícitos, de estudantes adolescentes sobre identidade e iniciação sexual a partir do uso do gênero binário como categoria analítica. Os dados foram obtidos a partir de um questionário semiestruturado aplicado a 110 estudantes do Ensino Fundamental II de escolas públicas da cidade de Itabaiana, SE. O questionário contém tópicos relativos à sociodemografia e utiliza a técnica de associação livre de palavras. As representações sociais dos participantes enfatizaram um perfil diferenciado entre meninos e meninas, sendo sexo, virgindade, masturbação e gravidez os temas que apresentam diferença significativa entre gêneros $(p<0,01)$. A análise de correspondência revelou diferentes padrões de associação sobre os temas relativos à sexualidade e corroboram a ideia que as desigualdades dos discursos entre gêneros são decorrentes de identidade e comportamento sexuais distintos, impostos pela cultura. Nossos dados ainda fornecem informações relevantes sobre sexualidade e gênero em espaços escolares e contribuem como linha de base para o entendimento das representações sociais da sexualidade de adolescentes do Nordeste do Brasil.

Palavras-chave: identidade sexual, representação social, análise de correspondência
\end{abstract}

Adolescent sexuality was addressed for a long time only from a biological and reproductive aspect. Currently, however, we cannot ignore the expression of different genders in the formation of identity and in individual behavior. The aim of this study is to identify ideas and values, explicit and implicit, of teenage students about identity and sexual initiation from the use of binary gender as an analytical category. Data were obtained from a semi-structured questionnaire applied to 110 elementary school students from public schools in the city of Itabaiana, SE. The questionnaire contains topics related to sociodemography and uses the technique of free word association. The social representations of the participants emphasized a different profile between boys and girls, with sex, virginity, masturbation and pregnancy being the themes that present a significant difference between genders $(p<0.01)$. Correspondence analysis revealed different patterns of association on themes related to sexuality and corroborates the idea that discrepancies between genders are due to distinct sexual identity and behavior, imposed by culture. Our data also provide relevant information on sexuality and gender in school spaces and contribute as a baseline for understanding the social representations of sexuality among adolescents in Northeast Brazil.

Keywords: sexual identity, social representation, correspondence analysis

\section{INTRODUÇÃO}

A sexualidade é algo intrínseco aos indivíduos, independente da cultura, idade, etnia e classe social, sendo, no entanto, encarada de maneira diferenciada em diferentes contexto culturais ao longo da história humana [1,2]. No passado a sexualidade era usualmente abordada considerando apenas seus aspectos biológicos e reprodutivos [3]. Entretanto, os estudos atuais tentam entender o desenvolvimento da sexualidade a partir dos aspectos culturais e suas influências na formação da identidade e no comportamento humano $[4,5]$.

$\mathrm{Na}$ adolescência, a manifestação da sexualidade é socialmente percebida como uma fase de transformações, com contornos ainda não claramente definidos [6, 7]. Entre as experiências corporais, emocionais, afetivas e amorosas que ocorrem no processo do desenvolvimento da sexualidade, a primeira relação sexual é considerada um marco nessa etapa da vida [8,9]. Mesmo 
não estando mais relacionada apenas ao matrimônio ou à reprodução, a "perda" da virgindade permanece ainda como uma fase de transição da adolescência à vida adulta $[3,10]$.

De modo geral, a sexualidade é culturalmente estabelecida e envolve as práticas eróticas, as relações afetivas e os objetos de desejo do indivíduo $[5,11]$. De modo semelhante o gênero também é estabelecido culturalmente e tem distinções entre os diferentes grupos humanos [12,13]. Assim como a sexualidade pode ser múltipla (e.g., heterossexualidade, homossexualidade, bissexualidade, etc.), a identidade de gênero pode ser entendida como binária (i.e., homem ou mulher) ou nãobinária (i.e., agênero, gênero fluído, andrógine, poligênero, pangênero, etc) $[14,15]$.

Dentro desse contexto, as questões de gênero têm se mostrado fundamentais no entendimento da identidade e comportamento sexual dos adolescentes [16, 17]. O conceito de "gênero" é entendido, neste trabalho, como uma construção social que uma dada cultura estabelece ou elege em relação ao que significa o ser "feminino" e o "masculino" [5, 12]. Nesse processo, os indivíduos são treinados e moldados, inclusive por meio dos sistemas educacionais, a refletir o desejo, a ideologia sexual e a noção de masculinidade e feminilidade dominantes $[18,19]$.

Apesar do conceito de gênero englobar atualmente as diversas maneiras de manifestação das identidades dos indivíduos [20,21], esse estudo considerou a terminologia de gênero binário como categoria analítica. Tal categoria engloba, além das diferenças biológicas, as particularidades comportamentais das diferentes noções do ser masculino e feminino, que são construídas histórica e culturalmente pelas diferentes sociedades $[11,20]$. $O$ uso desse conceito permite abandonar a explicação biológica como a responsável pela grande diferença existente entre os comportamentos e lugares ocupados por homens e mulheres nas sociedades humanas [7, 22].

Apesar das noções de "papéis" masculinos e femininos serem bastante aceitas socioculturalmente, suas definições são bastante simplistas e arbitrárias e não se relacionam necessariamente com a identidade dos sujeitos [23, 24]. Ao afirmar que o gênero institui a identidade do sujeito (assim como a etnia, a classe, ou a nacionalidade) pretende-se acenar a características dos sujeitos que vão além do mero desempenho de "papéis sociais", considerando a ideia do gênero no processo de construção do sujeito [11].

Buscar entender o comportamento dos sujeitos a partir dos "papéis sociais" considerados adequados e inadequados para meninos e meninas é desconsiderar as identidades plurais, que se transformam e que podem ser contraditórias [12, 19]. Além disso, presumir comportamentos considerados típicos para um determinado gênero implica em não se considerar as múltiplas formas com as quais os sujeitos podem assumir as masculinidades e as feminilidades, enviesando dessa forma a análise da identidade dos sujeitos $[5,13]$.

Neste estudo, empregou-se como suporte teórico o conceito de representações sociais proposto por Jodelet (2003)[25] e Moscovici (2010) [26], com o qual considera a análise das representações uma maneira de interpretar e pensar a realidade cotidiana a partir da atividade mental desenvolvida pelos indivíduos e grupos em relação a situações, eventos e objetos [27]. Essas representações resultam da interação social e retratam um recorte da realidade em sua dinâmica e diversidade em um determinado grupo de indivíduos [26, 28].

Apesar de não existir um modelo geral que permita compreender todas as dimensões da sexualidade [29], vários estudos têm procurado utilizar as representações sociais [18, 30-32], como forma de explicar o hiato existente entre intenção e comportamento sexual dos indivíduos [33]. As representações sociais se apresentam, assim, como uma abordagem importante nos estudos da identidade sexual de adolescentes, de forma que seja possível acessar conjuntos organizados e estruturados de crenças, opiniões, informações e atitudes que estes têm em relação à sua própria sexualidade [29, 34].

Nesse contexto, estudos sobre as representações sociais da sexualidade na adolescência são relevantes pela necessidade de evidenciar como estas são construídas socialmente por adolescentes de diferentes gêneros [7, 35]. Nesse momento de incertezas, esse estudo se faz ainda mais necessário, já que o poder público no Brasil tem inviabilizado políticas afirmativas relacionadas à educação sexual nas escolas e tem cerceado a discussão sobre a questão de gênero nos espaços públicos [36], dificultando, assim, o processo de construção da isonomia de direitos entre homens e mulheres, tanto no sentido biológico como no cultural [37].

O presente estudo, sob a perspectiva das representações sociais, se baseia na hipótese que as desigualdades dos discursos entre gêneros (masculino e feminino) são decorrentes da identidade e 
comportamento distintos dos sujeitos, impostos pela cultura local. Seu objetivo é o de compreender as representações sociais diante de vários temas relacionados à iniciação e identidade sexual de adolescentes escolares, usando gênero binário como uma categoria analítica.

\section{MATERIAL E MÉTODOS}

Trata-se de um estudo descritivo desenvolvido em seis escolas urbanas e rurais de Itabaiana, município mais populoso da região central de Sergipe, com cerca de 100.000 habitantes [38]. O Produto Interno Bruto (PIB) de Itabaiana reflete a importância econômica desse município para o estado de Sergipe, sendo sua economia baseada principalmente nas atividades de serviços e indústria $(94,5 \%)$, e setor agrícola $(5,5 \%)$ [38].

A escolha das escolas teve como critério selecionar instituições que ofertassem o Ensino Fundamental II, estivessem localizadas em comunidades com condições socioeconômicas distintas e participassem do programa Saúde e Prevenção nas Escolas (SPE). O SPE ${ }^{1}$ foi criado em 2003, em articulação conjunta entre o Ministério da Saúde (Coordenação Nacional de DST/Aids) e o Ministério da Educação, "com apoio da UNESCO e especialistas da área de educação e saúde com objetivo de reduzir a vulnerabilidade dos jovens, promovendo a saúde sexual e reprodutiva de forma ampla" [39, 40].

A amostragem foi realizada a partir da seleção aleatória de uma turma de $8^{\circ}$ ano do Ensino Fundamental por escola, com a aplicação de um questionário semiestruturado para todos os alunos da turma [41]. Optou-se por alunos do $8^{\circ}$ ano do Ensino Fundamental por serem essas turmas formadas por indivíduos acima de 12 anos e que já participam de projetos de educação sexual nas escolas [18]. O estudo contou com a participação voluntária de 110 adolescentes de ambos os gêneros. A estes adolescentes foi informado sobre os objetivos do estudo e foi aplicado o Termo de Consentimento Livre e Esclarecido (TCLE), assegurando-se o direito à confidencialidade, anonimato e privacidade [42].

O questionário semiestruturado aplicado a estes discentes abordava tópicos sobre sociodemografia (e.g., sexo, idade, estado civil, religião, etc.) e técnica de associação livre de palavras [43], utilizando como estímulo indutor os termos "sexo", "virgindade", "masturbação", "gravidez", "Infecções Sexualmente Transmissíveis (ISTs)", "aborto" e "homossexualidade".

As respostas dos questionários foram organizadas em categorias quantitativas para analisar as representações sociais dos adolescentes participantes, buscando testar a existência de diferenças entre os sujeitos. Empregou-se como suporte metodológico a teoria das representações sociais [25, 26], buscando-se avaliar como os sujeitos analisados estabelecem relação entre os "termos indutores" e as dimensões simbólicas compartilhadas [28, 44].

A análise e discussão dos dados foram efetuadas através da interpretação dos dados coletados, adotando um tratamento estatístico descritivo (i.e., frequência de resposta), distribuído sob a forma de tabelas, para uma melhor inspeção visual das variáveis estudadas [45]. Frequências de respostas para cada categoria foram determinadas pela contagem do número de adolescentes que usaram palavras ou expressões semelhantes para descrever os conceitos abrangidos por cada variável categórica [41]. As diferenças entre gêneros das representações sociais diante os termos indutores foram testadas pelo teste chi-quadrado de Pearson $(p<0,05)$ [43]. Somente as categorias mencionadas por mais de $5 \%$ dos entrevistados foram consideradas para discussão.

Análises de Correspondência Múltipla (ACM) foram conduzidas utilizando o software R e os pacotes "FactoMineR" e "factoextra", permitindo uma representação espacial do dados [46]. A ACM foi utilizada por ser uma ferramenta capaz de apresentar graficamente o modo como um conjunto de variáveis categóricas se inter-relaciona, por meio da disposição de suas categorias em um mapa com dois eixos [45]. Cada eixo dessa análise explica uma parcela da variância contida nos dados e a orientação de cada ponto no mapa é definida pela distância Euclidiana. A análise de correspondência avança na análise univariada (i.e., teste de chi-quadrado), ao correlacionar positiva

\footnotetext{
${ }^{1}$ Posteriormente, o SPE impulsionou a criação do Programa Saúde na Escola (PSE), com a 'finalidade de contribuir para a formação integral dos estudantes da rede pública de educação básica por meio de ações de prevenção, promoção e atenção à saúde” (Decreto Presidencial nº 6.286/2007) [40].
} 
e negativamente os sete termos indutores acima listados em quatro quadrantes, avaliando a contribuição de cada variável categórica na construção do mapa de associações entre os gêneros.

\section{RESULTADOS}

Os adolescentes que compõem o grupo analisado $(\mathrm{N}=110)$ tem idade entre 12 a 18 anos (média de 13,9 e DP $=1,8)$, sendo em sua maioria do sexo feminino (67\%), solteiros $(98 \%)$ e moram com os pais (98\%). Destaca-se uma maior porcentagem de adolescentes que se reconhecem como católicos $(76 \%)$, seguida de evangélicos $(19 \%)$ e outras religiões $(5 \%)$. Em relação ao comportamento sexual, $22 \%$ deles afirmaram já ter iniciado sua atividade sexual (21 meninos e quatro meninas). Os adolescentes também afirmaram que costumam obter informação sobre sexo com amigos (38\%), na internet (26\%), na escola (18\%), com a família (11\%), e "outros meios" (7\%) não especificados.

As expressões mencionadas pelos participantes para os sete termos indutores foram agrupadas em diferentes variáveis categóricas (Tabelas 1 e 2), tendo "sexo" e "virgindade" o maior número de categorias (nove), "gravidez" (oito), "aborto" (sete) "masturbação" (seis), "IST" (quatro), e "homossexualidade" (cinco). Diferenças significativas entre meninos e meninas foram observadas para os termos sexo, virgindade, masturbação e gravidez (Tabela 1). No entanto, os termos IST, aborto e homossexualidade não apresentaram diferença estatística entre gênero (Tabela 2). Para todos os termos indutores não foi possível detectar diferenças significativas entre os termos indutores e o tipo de religião dos adolescentes $(p>0,05)$.

As evocações relacionadas ao termo sexo mais citadas pelos meninos foi que "sexo é algo prazeroso e gostoso" (31\%) e pelas meninas que "sexo é o meio de gerar uma criança" (19\%). Para os meninos o termo sexo foi associado principalmente a aspectos positivos como "prazer", e "necessidade", já para as meninas, o termo sexo apresentou menções contraditórias, sendo associado desde "amor" e "prazer", como também "obrigação".

De acordo com o agrupamento de palavras em torno do termo virgindade, percebe-se que a representação social desse grupo está pautada principalmente na diferenciação sobre a iniciação sexual no âmbito feminino e masculino (para 39\% dos meninos) e na valoração feminina associada à manutenção do hímen (para 34\% das meninas). Destacam-se também representações associadas à virgindade, tais como "mulher virgem é mais fiel" (para 22\% e 19\% dos meninos e meninas, respectivamente) e "virgindade é coisa do passado" (segundo, respectivamente, 14\% e 12\% dos meninos e meninas).

As maiores diferenças das representações sociais entre gêneros se referem às evocações ao termo masturbação. Isso porque, para os meninos a auto estimulação sexual é manifestada principalmente com menções de "prazer" e "gostoso" (58\%), enquanto para as meninas a masturbação evoca sentimento como "proibido" (41\%), "pecado" (27\%) e "nojento" (26\%).

Para as meninas, o termo gravidez é expresso de forma ambígua e está diretamente relacionado aos diversos "papéis" femininos, tais como, por um lado, a noção de que "a mulher nasceu para isso" $(23 \%)$ e a ideia de gravidez como sentimento de "felicidade" $(20 \%)$, mas, por outro lado, a possibilidade de "contracepção por comprimido" (16\%), "abandono dos estudos" (16\%) e "aumento de responsabilidades" (14\%). Para os meninos, o termo gravidez parece ser uma responsabilidade apenas da mulher (33\%), embora sejam também evocados a possibilidade de "contracepção por camisinha" (22\%) e a "necessidade do trabalho masculino" (22\%), como consequências.

As representações sociais evocadas pelos adolescentes à sigla IST não apresentaram diferença estatística entre os gêneros, estando relacionadas principalmente à Síndrome da Imunodeficiência Adquirida (AIDS) para $47 \%$ dos meninos e 38\% das meninas). Além disso, os respondentes relacionam IST com ideias de doenças "incuráveis", "transmissíveis", e que poderiam ser "evitadas com uso da camisinha" (Tabela 2). 
Tabela 1: Frequência de respostas de adolescentes escolares do município de Itabaiana, SE, partir de termos indutores. Diferenças significativas entre gêneros pelo teste chi-quadrado de Pearson $(N=110)$.

\begin{tabular}{|c|c|c|c|c|}
\hline \multirow{2}{*}{ Termos indutores/variáveis categóricas } & \multicolumn{2}{|c|}{ Meninos } & \multicolumn{2}{|c|}{ Meninas } \\
\hline & $\mathbf{n}$ & $\%$ & $\mathbf{n}$ & $\%$ \\
\hline \multicolumn{5}{|l|}{ Termo indutor: $\operatorname{Sexo}(p=0,003)$} \\
\hline Algo prazeroso e gostoso & 11 & $31 \%$ & 7 & $9 \%$ \\
\hline Relação sexual apenas entre homem e mulher & 8 & $22 \%$ & 9 & $12 \%$ \\
\hline É uma necessidade para os homens & 5 & $14 \%$ & 2 & $3 \%$ \\
\hline Meio de gerar uma criança & 4 & $11 \%$ & 14 & $19 \%$ \\
\hline Relação sexual entre duas pessoas & 4 & $11 \%$ & 7 & $9 \%$ \\
\hline É um pecado & 1 & $3 \%$ & 6 & $8 \%$ \\
\hline Um impulso incontrolável & 1 & $3 \%$ & 5 & $7 \%$ \\
\hline Uma obrigação do casamento & 1 & $3 \%$ & 12 & $16 \%$ \\
\hline Uma prova de amor & 1 & $3 \%$ & 12 & $16 \%$ \\
\hline \multicolumn{5}{|l|}{ Termo indutor: Virgindade $(p<0,001)$} \\
\hline Homens não precisa ser virgem, mulheres sim & 14 & $39 \%$ & 0 & $0 \%$ \\
\hline Mulher virgem é mais fiel & 8 & $22 \%$ & 14 & $19 \%$ \\
\hline Para mim não faz diferença & 5 & $14 \%$ & 1 & $1 \%$ \\
\hline Coisa do passado & 5 & $14 \%$ & 9 & $12 \%$ \\
\hline Para não correr o risco de pegar IST & 1 & $3 \%$ & 1 & $1 \%$ \\
\hline Importante para o respeito da mulher & 1 & $3 \%$ & 9 & $12 \%$ \\
\hline É pecado transar sem estar casado & 1 & $3 \%$ & 6 & $8 \%$ \\
\hline A mulher virgem tem mais valor & 1 & $3 \%$ & 25 & $34 \%$ \\
\hline Perdem a virgindade deve doer muito & 0 & $0 \%$ & 9 & $12 \%$ \\
\hline \multicolumn{5}{|l|}{ Termo indutor: Masturbação $(p<0,001)$} \\
\hline É gostoso e dá muito prazer & 21 & $58 \%$ & 0 & $0 \%$ \\
\hline Pode causar impotência & 7 & $19 \%$ & 1 & $1 \%$ \\
\hline As pessoas fazem escondido & 6 & $17 \%$ & 4 & $5 \%$ \\
\hline É pecado & 1 & $3 \%$ & 20 & $27 \%$ \\
\hline Fazer isso é nojento & 1 & $3 \%$ & 19 & $26 \%$ \\
\hline Não deve fazer para não perder a virgindade & 0 & $0 \%$ & 30 & $41 \%$ \\
\hline \multicolumn{5}{|l|}{ Termo indutor: Gravidez $(p<0,001)$} \\
\hline Culpa da mulher que não se previne & 12 & $33 \%$ & 5 & $7 \%$ \\
\hline Camisinha evita a gravidez & 8 & $22 \%$ & 2 & $3 \%$ \\
\hline O homem tem que trabalhar para sustentar & 8 & $22 \%$ & 1 & $1 \%$ \\
\hline A mulher nasceu para isso & 3 & $8 \%$ & 17 & $23 \%$ \\
\hline Aumento de reponsabilidades & 2 & $6 \%$ & 10 & $14 \%$ \\
\hline Abandono dos estudos & 1 & $3 \%$ & 12 & $16 \%$ \\
\hline É uma felicidade para casamento & 1 & $3 \%$ & 15 & $20 \%$ \\
\hline Para evitar deve tomar comprimido & 1 & $3 \%$ & 12 & $16 \%$ \\
\hline
\end{tabular}

As representações sociais relacionadas ao tema aborto também não apresentaram diferenças estatísticas entre os gêneros, e sua consonância é estabelecida pela sua visão da interrupção da gravidez como "crime" (para 44\% e 32\% dos meninos meninas, respectivamente), "um ato de irresponsabilidade" (segundo, respectivamente, $31 \%$ e $22 \%$ dos meninos e meninas) ou "pecado" (para $17 \%$ e $15 \%$ dos meninos e meninas, respectivamente).

Não foi possível detectar diferenças estatísticas, entre os gêneros, relacionadas ao termo homossexualidade. As principais evocações citadas pelos meninos foi "pecado" (28\%), "doença" $(22 \%)$ e "vergonha para família" (22\%). Entre as meninas chama atenção a alta frequência de evocações sobre a condição homoafetiva como uma opção individual (41\%), não sendo atribuído a priori, julgamento moral ou religioso sobre a homossexualidade. 
Tabela 2: Frequência de respostas de adolescentes escolares do município de Itabaiana, SE, a partir de termos indutores. Ausência de diferenças significativas entre gêneros pelo teste chi-quadrado de Pearson $(N=110)$.

\begin{tabular}{|c|c|c|c|c|}
\hline \multirow{2}{*}{ Termos indutores/variáveis categóricas } & \multicolumn{2}{|c|}{ Homens } & \multicolumn{2}{|c|}{ Mulheres } \\
\hline & $\mathbf{n}$ & $\%$ & $\mathbf{n}$ & $\%$ \\
\hline \multicolumn{5}{|l|}{ Termo indutor: $I S T(p=0,207)$} \\
\hline AIDS & 17 & $47 \%$ & 28 & $38 \%$ \\
\hline Doenças que não tem cura & 8 & $22 \%$ & 9 & $12 \%$ \\
\hline Doenças que são evitadas com camisinha & 5 & $14 \%$ & 21 & $28 \%$ \\
\hline Doenças que se transmite facilmente & 6 & $17 \%$ & 16 & $22 \%$ \\
\hline \multicolumn{5}{|l|}{ Termo indutor: Aborto $(p=0,268)$} \\
\hline Matar uma criança é crime & 16 & $44 \%$ & 24 & $32 \%$ \\
\hline Irresponsabilidade na hora de transar & 11 & $31 \%$ & 16 & $22 \%$ \\
\hline Matar uma criança é pecado & 6 & $17 \%$ & 11 & $15 \%$ \\
\hline Falta de condições & 1 & $3 \%$ & 5 & $7 \%$ \\
\hline Quem sofre é a criança & 1 & $3 \%$ & 5 & $7 \%$ \\
\hline Uma vergonha uma mulher que faz isso & 1 & $3 \%$ & 7 & $9 \%$ \\
\hline É um perigo para mulher & 0 & $0 \%$ & 6 & $8 \%$ \\
\hline \multicolumn{5}{|l|}{ Termo indutor: Homossexualidade $(p=0,071)$} \\
\hline É pecado & 10 & $28 \%$ & 17 & $23 \%$ \\
\hline Isso é uma doença & 8 & $22 \%$ & 5 & $7 \%$ \\
\hline Uma vergonha para família & 8 & $22 \%$ & 9 & $12 \%$ \\
\hline É uma opção de cada um & 6 & $17 \%$ & 30 & $41 \%$ \\
\hline A pessoa já nasce assim & 4 & $11 \%$ & 13 & $18 \%$ \\
\hline
\end{tabular}

As relações acima entre os diferentes termos e associações induzidas também se refletem nos resultados da ACM (Figura 1). Os mapas da análise de correspondência demonstram uma separação clara entre meninos e meninas, correlacionando positivamente e negativamente os sete termos indutores. A figura $1 \mathrm{~A}$ representou $78,5 \%$ da variação das representações sociais femininas. O Dim 1, responsável por 40,4\% da variância, correlacionou-se positivamente com os termos gravidez e IST e, negativamente, com virgindade, sexo, masturbação, homossexualidade e aborto. O Dim 2, responsável por $38,1 \%$ da variação, correlacionou-se positivamente com sexo, IST e virgindade e, negativamente, com virgindade, sexo, masturbação, homossexualidade e aborto.
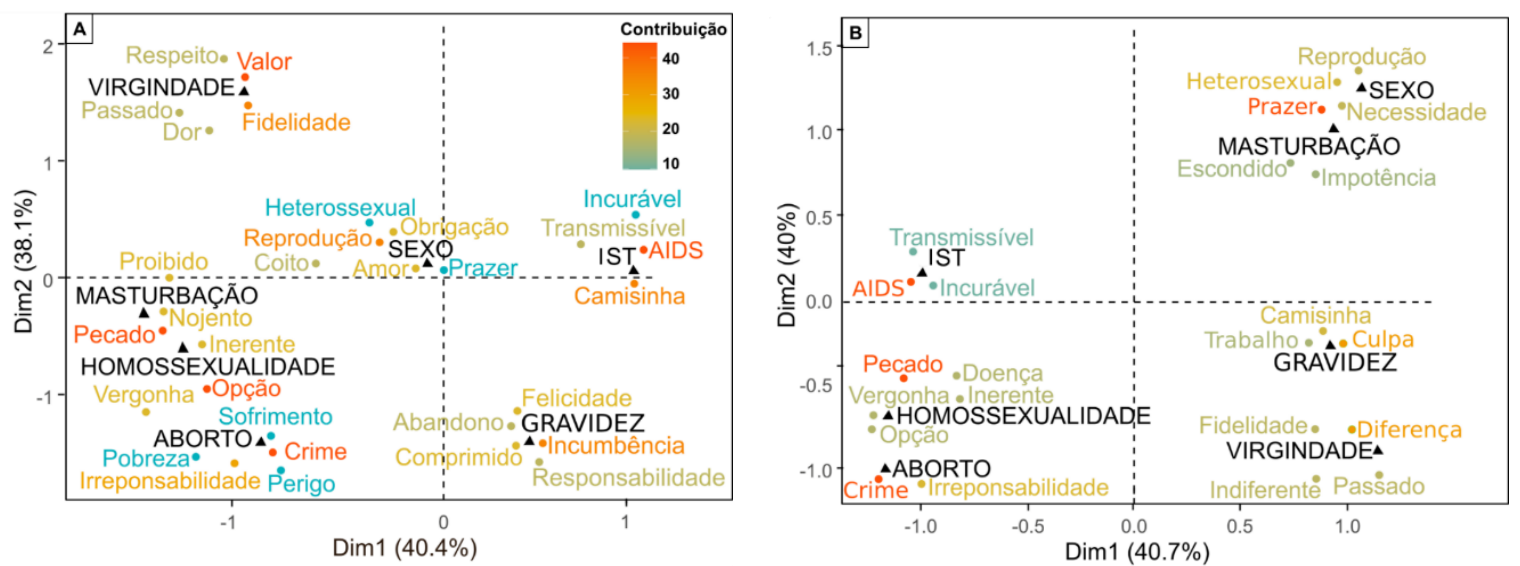

Figura 1: Análise de Correspondência Múltipla a partir das respostas de meninas $(A)$ e meninos (B), induzidas pela técnica de associação livre de palavras. As palavras em preto representam os termos indutores e as palavras em cores representam as respostas dos adolescentes (variáveis categóricas).

A Figura 1B representou 80,7\% da variação das representações sociais masculinas. O Dim 1, responsável por $40,7 \%$ da variância, correlacionou-se positivamente com os termos sexo, 
masturbação, gravidez e virgindade e, negativamente, com os termos IST, homossexualidade e aborto. O Dim 2, responsável por $40 \%$ da variação, correlacionou-se positivamente com sexo, masturbação e IST e, negativamente, com homossexualidade, aborto, gravidez e virgindade.

\section{DISCUSSÃO}

À semelhança de outros estudos [8, 47], a prevalência de meninas como respondentes dos questionários é reflexo da proporção maior de estudantes do sexo feminino no estado de Sergipe [39]. A maioria dos adolescentes se reconhece como católicos e evangélicos, retratando a divisão religiosa no Brasil [48]. Verifica-se uma maior participação no estudo, de adolescentes solteiros que vivem com os pais, sendo os jovens com vida sexualmente ativa, os que apresentam maior diversidade de respostas na área da sexualidade. Apesar da maior parte dos respondentes ser do grupo feminino, os meninos são a maioria dos que afirmaram já terem iniciado a vida sexual. Uma possível explicação para a mais tardia iniciação sexual das meninas reside na influência e controle social mais eficiente diante ao corpo e sexualidade feminina [7, 17].

Apesar de suas escolas participarem do programa SPE, a maioria dos adolescentes parece buscar os amigos, principalmente os que já têm vida sexual ativa, para obter informações relacionadas à sexualidade. Assim como em outros estudos [4, 49], nossos dados retratam a natureza empírica do conhecimento sobre sexualidade entre os adolescentes e o elo de confiança entre indivíduos com idades semelhantes $[47,50]$. A família e a escola são os principais meios para aquisição de informação e valores para viver em sociedade, mas estas instituições nem sempre correspondem às necessidades dos jovens, fazendo com que os mesmos recorram a outras fontes de informação sobre sexualidade $[18,29]$. Embora positivo, o contato e a troca entre colegas enfrentando as mesmas angústias e dificuldades dessa fase pode representar, também, a disseminação de mitos sobre procedimentos contraceptivos e detecção e tratamento de ISTs, além de comportamentos estereotipados sobre o que significa ser "homem" ou o que se espera de uma "mulher de respeito".

As representações sobre as relações sexuais são influenciadas pela vida social, econômica e cultural de diversas maneiras [44, 49]. Para o grupo masculino desse estudo, o termo sexo está representado por sentimentos de "prazer" e "necessidade", demonstrando um significado fundamental e profundo do coito no processo de construção da identidade masculina e da postura ativa do homem no processo sexual [13, 21]. Como elementos periféricos, aparecem, também expressões relacionadas à "reprodução" e "heterossexualidade" (Figura 1A). De forma geral, os meninos valorizam o sexo com uma relação apenas entre homem e mulher e que deve ocorrer com o propósito de gerar filhos, embora considerem normal praticá-lo apenas pelo prazer e sem compromisso, como parte das "atribuições" masculinas [34].

O grupo feminino apresentou, como núcleo central das representações sobre sexo, as expressões "amor" e "reprodução", evidenciando que acreditam nas relações sexuais com o propósito de gerar filhos e nos relacionamentos sexuais embasados no amor, carinho e afetividade [51]. Surpreende, como elemento periférico, o surgimento da expressão "obrigação" (Figura 1B), que reflete uma visão mais conservadora sobre a necessidade de as mulheres "servirem" sexualmente seus parceiros, como parte das atribuições femininas [34, 52]. Por outro lado, outros elementos, como "heterossexual" e "prazer", mostram que o grupo feminino percebe o desejo, sobretudo entre homens e mulheres, como parte integrante e representativa do sexo, diferindo de gerações anteriores, que não expressavam a própria sexualidade com liberdade [9].

Assim como em outros estudos de representação social [9, 53], para os homens o corpo feminino tem um significado fortemente ligado ao desejo e ao prazer, confirmando a ideia que o universo masculino relaciona o sexo à atração física e ao prazer instantâneo. Já em outros estudos [30, 54], o aspecto romântico do sexo entre as mulheres surge como um enviesamento perceptivo sobre a sexualidade, no qual confiam ao parceiro o direito ao seu corpo. Essa diferenciação entre meninos e meninas sobre as relações sexuais pode ser justificada pela construção social/cultural da masculinidade e feminilidade, numa sociedade que demarca os "papéis sexuais" de forma rígida e estereotipada e considera o corpo feminino como um dispositivo de controle social $[8,53]$.

Nas representações sociais nos grupos ocidentais, a iniciação sexual é socialmente percebida como um rito de passagem, cujos contornos ainda não estão claramente definidos [6, 29]. Em tais 
representações se dão a afirmação da virilidade e feminilidade, perpassando pelos sentidos identitários diversos, como "ser homem" ou "ser mulher" $[2,50]$. No entanto, diversos fatores, individuais e sociais, influenciam a percepção sobre a iniciação sexual entre os jovens [17]. No tocante à virgindade, o grupo masculino desse estudo centrou seu discurso na diferenciação entre homens e mulheres no processo de iniciação sexual. Aparecem, como elementos periféricos, expressões que englobam a relação da virgindade com a fidelidade feminina e discursos que demarcam a virgindade como "coisa do passado" (Figura 1B).

Entre as meninas, também é aceita uma condição de mais valor e moral da mulher em função da manutenção do hímen. Expressões como "valor", "fidelidade" e "respeito", em resposta ao termo virgindade, foram as mais frequentemente apontadas pelo grupo feminino. Apesar de outros aspetos periféricos surgirem integrados à sensação de "dor" na primeira relação (Figura 1A), seu conteúdo central não é alterado e legitima a ideia da manutenção do hímen como uma virtude ou como uma "poupança", que deve ser guardada para o casamento [18, 29]. Outras representações sociais apontadas pelas meninas apresentam também, como para parte dos meninos, a virgindade como "coisa do passado". No entanto, percebe-se que a iniciação sexual antes do casamento ainda parece ser um tabu no grupo feminino, sendo o vestido branco um dos principais símbolos sociais de pureza e inexperiência sexual feminina [3, 23].

A família influencia de forma determinante os "papéis sexuais" dos filhos, já que a sociedade ainda demarca as "funções" diferentemente para meninos e meninas [29, 50]. Aos meninos é permitido, se não estimulado, o interesse precoce pela iniciação sexual, já que os pais, os amigos e a mídia naturalizam a expressão de sua sexualidade e aponta as relações sexuais como representação da masculinidade [5, 12]. Já os corpos das meninas são, desde cedo, controlados, seja pela família, pelos amigos e/ou pelos meios de comunicação $[28,50]$. O tabu que pesa sobre a iniciativa sexual das mulheres reflete a subordinação e o controle que setores dominantes da sociedade estabelecem sobre os instintos e desejos femininos e que tem como consequência representações sociais que afastam a sexualidade da identidade feminina [17, 18].

Assim como a virgindade, a masturbação envolve aspectos divergentes entre homens e mulheres, nas quais dogmas religiosos a favor da pureza e controle da castidade parecem ser mais determinantes [55]. Apesar da assimetria de gênero quanto ao tema, a masturbação tem um importante função no desenvolvimento sexual durante a adolescência, servindo não só para descarregar a tensão sexual, como também na definição da autoimagem sexual [3, 8]. Neste estudo, nenhuma das meninas entrevistadas afirmaram masturbar-se, temendo que a autoestimulação sexual pudesse de alguma forma romper o hímen. Outros elementos periféricos quanto à masturbação, envolvem expressões de "pecado" e "nojo" (Figura 1A), e reafirmam a representação social negativa do grupo feminino quanto ao tema.

No grupo masculino, o núcleo central das representações sobre masturbação definiu-se pela expressão "é gostoso e dá muito prazer", evidenciando a associação da autoestimulação sexual ao prazer físico, postura incentivada pela sociedade como forma de manifestação da virilidade masculina [51]. Por outro lado, outros elementos periféricos, como "escondido" e "impotência", destacam condutas sociais ambíguas sobre o tema, entre os meninos (Figura 1B). Sendo assim, se por um lado a masturbação é estimulada nos homens como símbolo de masculinidade, por outro, parece sofrer, ao menos em parte, os efeitos dos dogmas religiosos, ao encarar o tema como pecado e/ou como atividade potencialmente geradora de doenças $[13,55]$.

A diferença, entre meninos e meninas, das representações quanto à masturbação pode também ser associada ao tratamento diferenciado dos pais em relação a filhos e filhas [54]. Apesar de grande parte dos pais fingirem que não percebem o afloramento da sexualidade dos seus filhos, ao menino é dado o direito do autoconhecimento do seu corpo desde criança [50]. Na adolescência, a autoestimulação das zonas erógenas é permitida ao homem, desde que às escondidas [8]. De maneira contrária, os pais cerceiam às meninas o direito do seu autoconhecimento corporal durante todo o período de formação da sua sexualidade [52]. Quando crianças, as meninas são reprimidas ao tocar em sua própria genitália e, quando adolescentes, são convencidas de que a autoestimulação pode romper seu hímen e torná-las promíscuas, gerando assim representações sociais negativas no grupo feminino sobre essa temática $[3,18]$.

Nas relações sexuais, o maior medo entre os adolescentes está relacionado à gravidez, devido aos desafios relacionados à concepção e criação da prole [9]. Assim como em outros estudos [4, 
56], o termo gravidez apresentou diferença significativa das representações entre os gêneros, refletindo toda a carga cultural e as diferentes "funções" e "papéis" destinados a homens e mulheres. A gravidez foi associada a "incumbência" e "felicidade" no grupo feminino (Fig. 1A), ao enfatizarem a concepção de um bebê como um "papel" inerente à mulher, ou evocando a gestação como um meio de trazer alegria ao casal, outros estudos também observaram esse padrão de representação social em grupos femininos [54]. Práticas preventivas, como o uso de pílulas anticonceptivas, foram pontuadas pelas meninas a fim de evitar uma gravidez indesejada. Sentimentos negativos relacionados à gravidez não desejada perpassam pelo medo das meninas quanto às reações dos pais, o julgamento da família e vizinhos, a sensação de dor na hora do parto, o aumento de responsabilidades para criar um bebê e o receio do abandono escolar $[51,55]$.

O grupo masculino apresenta, como núcleo central sobre a gravidez, o "papel" feminino no processo de contracepção e a responsabilidade da mulher no caso de uma gravidez indesejada. Nas representações masculinas fica claro que a mulher é a grande responsável pela preparação "da cena", na qual o homem seria apenas "convidado" a atuar [53]. Os meninos destacam ainda a gravidez como consequência do sexo sem camisinha, mostrando que percebem os riscos das relações sexuais sem proteção (Figura 1B). Aparece também, como elemento periférico das suas representações, a expressão "necessidade do trabalho masculino", refletindo o "papel" do homem como provedor e protetor da família e do lar [53, 57]. Apesar disso, contestando os modelos tradicionais do "papel" masculino, vem crescendo no Brasil o número de lares chefiados e providos por mulheres, revelando novos arranjos familiares em torno do "papel social" feminino $[58,59]$.

A assimetria de representações entre meninos e meninas quanto à gravidez evidencia a diferença dos "papéis sociais" instituídos a homens e mulheres, sendo seus efeitos negativos mais evidentes no grupo feminino [51]. No que se refere à situação conjugal, a gravidez na adolescência tem sido apontada como um importante fator catalizador da união ou separação entre os casais [57]. As atitudes masculinas diante da gestação podem variar desde o entusiasmo até a resistência [59]. Quando o pai aceita a criança, a evolução gestacional se dá de maneira mais tranquila, não sendo observados grandes impactos na vida da mulher [59,60]. Já a recusa do homem para aceitar a paternidade pode gerar conflitos entre o casal e ocasionar uma sobrecarga de responsabilidade na vida das adolescentes [61].

O uso de métodos contraceptivos é um dos aspectos cruciais na análise da gravidez e das ISTs na adolescência $[9,16]$. Uma grande quantidade de materiais e campanhas com nível de informação sobre os principais preservativos e formas de contracepção tem sido produzidas e divulgadas para e entre os adolescentes brasileiros [4, 32]. No entanto, apenas essa exposição não tem garantido uma diminuição na frequência dos casos de gravidez não desejadas e de ISTs entre os jovens [51]. Em se tratando de ISTs, as representações foram semelhantes entre os dois gêneros, sendo o núcleo central constituído pela "AIDS". Os adolescentes destacaram a AIDS com principal infecção decorrente do sexo sem camisinha. Tal fato ocorre devido à função do Estado brasileiro no tratamento da infecção e/ou nos investimentos públicos nas campanhas publicitárias de prevenção (50). Apesar de outros elementos periféricos (i.e., "transmissível", incurável" e "camisinha") confirmarem a semelhança das representações entre os adolescentes acerca das ISTs (Figuras 1AB), nossos dados apontam para os vários obstáculos emocionais e culturais entre meninos e meninas, na ação do uso de preservativos no momento das relações sexuais [60].

No grupo masculino analisado, pode-se observar uma representação de que o "sexo com camisinha" é ruim, desconfortável e não oferece prazer [54]. Ao contrário, o "sexo sem camisinha" proporciona prazer e satisfação, mesmo que haja riscos de contrair uma infecção ou da ocorrência de uma gravidez indesejada. No grupo feminino, as representações sociais apontam para a ausência de relação do uso de métodos preservativos com a diminuição do prazer, sendo estes encarados positivamente, como importantes métodos para evitar uma IST ou uma gravidez não desejada. Mesmo dentro de um novo contexto, onde a relação é mais aberta o medos e vontades de ambos parceiros podem ser negociados, homens e mulheres têm claras distinções representacionais acerca do uso de métodos preservativos. Isso porque, a negociação do uso do preservativo esbarra em padrões sociais pautados nas relações de gênero, vulnerabilizando particularmente as mulheres [62]. As meninas declaram que não pedem aos seus parceiros que usem preservativos por vergonha, para "não quebrar o clima", ou por entender que a iniciativa deva ser dos meninos [32]. Fatores como baixa autoestima, medo de perder o parceiro e submissão à vontade masculina tem implicado 
na aceitação feminina em ter relações sexuais sem o uso de preservativos, mesmo ciente dos riscos associados [18]. O extremo da submissão das mulheres e o excesso de poder masculino tem evidenciado relações abusivas, psicológica, moral ou sexualmente, às quais muitas adolescentes ainda são submetidas, sem o perceberem [63, 64].

Em se tratando de aborto, as representações sociais foram semelhantes entre os grupos masculino e feminino, sendo o núcleo central marcado pela expressão "crime" (Figuras 1A-B). Elementos periféricos, como "irresponsabilidade" e "pecado", reafirmam os aspectos negativos relacionados ao tema para os dois grupos e destacam a influência dos preceitos religiosos sobre as representações sociais dos adolescentes [7, 61]. Outros elementos periféricos, citados principalmente pelas meninas, atribuem ao aborto expressões como "vergonha", "perigo para mulher", "sofrimento" e a "falta de condições", refletindo, assim, uma visão ambígua do grupo feminino sobre o tema [57]. Isso porque, se por um lado as meninas julgam negativamente a mulher que decide interromper a gravidez, por outro reconhecem o sofrimento feminino (e.g., risco de vida, falta de apoio e pressão psicológica por parte do parceiro e/ou família).

$\mathrm{O}$ debate sobre o aborto, dependendo da época, congrega maior ou menor visibilidade social, podendo a interrupção da gravidez ser considerada um direito a saúde reprodutiva e/ou um direito sobre o corpo feminino [37, 65]. No Brasil, as questões relacionadas ao aborto são fundamentadas na tradição judaico-cristã e seu debate ainda é centralizado na questão da manutenção da vida do feto [61]. As representações sociais sobre o tema explicitam o julgamento das mulheres que optam pela interrupção da gravidez e também retratam os três principais aspectos morais e religiosos associados ao aborto [29, 36]: 1) questões biológicas, que entram em conflito com a ideia do amor incondicional e instintivo da mãe para seu filho; 2) a maternidade como um dom da mulher e/ou como manifestação do amor divino (i.e., amor de Maria pelo seu filho Jesus); e 3) questões relacionadas à morte, tema ainda difícil para a humanidade [24].

Os princípios judaico-cristãos que influenciam o comportamento dos jovens em relação ao aborto parecem ser os mesmos que fundamentam as representações sociais dos adolescentes quanto à homossexualidade $[19,66]$. Representações sociais negativas quanto à natureza da homossexualidade foram observadas entre meninos e meninas e evidenciam a presença de preconceito entre os adolescentes (Figuras 1A-B). Apesar dos dois grupos não apresentarem diferenças estatisticamente significativas quanto à condição homossexual, o núcleo central das representações do grupo masculino foi constituído principalmente por expressões como "pecado", "doença" e "vergonha para família". No grupo feminino, o núcleo central sobre a homossexualidade, foi marcado por expressões como "opção" e "pecado". Expressões como "a pessoa já nasce assim", "vergonha para família" e "isso é uma doença" aparecem como termos periféricos nas representações sociais femininas.

Representações sociais que refletem a estranheza acerca da homossexualidade residem no caráter de ameaça de se perder as referências familiares, no comprometimento à continuidade geracional e no risco de não aceitação em seu grupo social [35, 67]. Tais representações acerca da homossexualidade são compostas por diferentes princípios, sendo os principais o religioso (homossexualidade como pecado), psicológico (homossexualidade como doença ou distúrbio), biológico (homossexualidade relacionada a fatores hereditários), ético-moral (a homossexualidade viola valores morais e tradicionais) e psicossocial (homossexualidade relacionada com aspectos identitários) [19, 68].

Apesar das questões que envolvem a homossexualidade ainda causarem estranhamento em diferentes contextos sociais, a discussão sobre o tema é importante para a reflexão acerca dos modelos projetados para homens e mulheres na sociedade sobre o tema [11, 36]. Isso é particularmente importante em um contexto em que iniciativas visando combater esse preconceito no ambiente escolar, como o projeto Escola sem Homofobia, parte do programa Brasil sem Homofobia do governo federal criado em 2004 [69], foi descontinuado em parte devido ao forte preconceito gerando distorções, amplamente divulgadas, como o "kit gay" [70].

De maneira geral, o estudo das representações sociais têm a função de compreender a realidade, orientar e conduzir o comportamento das pessoas a partir dos aspectos simbólicos e culturais [26, 44]. Tais representações são influenciadas por fatores históricos, econômicos, sociais, políticos e ideológicos e são capazes de refletir diferentes aspectos de assuntos cotidianos, no modo como os indivíduos interpretam, tomam decisões e posicionam-se frente a esses assuntos [25, 27]. 
Neste sentido, as análises efetuadas com os dados obtidos permitiram apontar diferentes representações estruturadas e organizadas entre meninos e meninas da cidade de Itabaiana, SE, com relação aos diversos temas abordados nesse estudo. Apesar de haver representações centrais, ora distintas, ora comuns, elaboradas coletivamente pelos adolescentes para temas como "sexo", "virgindade", "masturbação", "gravidez", "ISTs", "aborto" e "homossexualidade", observa-se, com base na Teoria das Representações Sociais [25, 26], que em tais representações estão diretamente implicados os "papéis sociais" que são socialmente construídos e compartilhados pelo grupo estudado.

Os critérios considerados para a identificação das representações sociais desses adolescentes, discentes do Ensino Fundamental, permitem-nos identificar representações generalizadas, coletivamente geradas, e interpretar os discursos desses indivíduos com base em valores, crenças e mitos compartilhados pelo grupo social [29]. Fica evidente que, apesar das mudanças que têm ocorrido em torno das identidades de gênero na sociedade, as noções, comportamentos e representações dos adolescentes, mesmo antes de iniciar a vida sexual, ainda são guiadas e construídas a partir das bases sociais antigas, há muito tempo instauradas e reconstruídas até os dias de hoje $[11,20]$.

\section{CONCLUSÃO}

O presente estudo fornece informações valiosas sobre representações sociais de um grupo de adolescentes do interior de Sergipe relacionadas à iniciação e identidade sexual, a partir do uso do gênero binário como categoria analítica. Apesar de nossa análise limitar a discussão a uma perspectiva cisgênero, sem englobar a transgeneridade e as identidades não-binárias, nossos achados complementam dados pretéritos sobre o entendimento de algumas representações de adolescentes do nordeste do Brasil.

Os resultados deste estudo sustentam a ideia de que as representações sociais são construídas a partir das experiências e valores compartilhados pela sociedade. Tanto a análise univariada (i.e., teste $\mathrm{X}^{2}$ ) como a multivariada (i.e., ACM) forneceram informações que permitem identificar diferença estatística significativa, entre meninos e meninas, quanto aos temas "sexo", "virgindade", "masturbação" e "gravidez" ( $p<0,01)$, e similaridade estatística aos temas "IST", "aborto" e "homossexualidade" $(p>0,05)$. Embora essa investigação apresente evidências para a sustentação da hipótese de que as desigualdades dos discursos entre meninos e meninas são decorrentes das diferenças identitárias e comportamentais, nossos dados não refletem, necessariamente, padrões gerais para os adolescentes brasileiros.

O estudo levanta aspectos importantes das representações sociais de jovens estudantes do Ensino Fundamental sobre diversos aspectos relacionados à sexualidade, os quais devem ser considerados como ponto de partida de ações e projetos de educação sexual. Dessa forma, a compreensão da forma como os adolescentes sentem, vivenciam e percebem sua sexualidade, com informações relevantes sobre a iniciação e a identidade sexual desses jovens para a sua saúde sexual e bem-estar psicossocial, pode contribuir para a elaboração de planos de educação sexual mais contextualizados.

Nesse contexto, nosso estudo avança em questões importantes relacionadas às diferenças dos "direitos" e "deveres" sexuais entre homens e mulheres, tendo como linha de base as representações sociais de um grupo usualmente pouco enfocado nas pesquisas sobre sexualidade, adolescentes vivendo no interior do nordeste brasileiro, distante dos grandes centros urbanos, e que, em sua maioria, não iniciaram ainda a vida sexual. Considerando a alta frequência de casos de gravidez e o crescente número de ISTs entre adolescentes no Brasil, ressalta-se a importância de estudos que visem compreender as representações desses jovens com relação a esses temas de modo a possibilitar uma complementaridade entre o conhecimento científico e sua aplicação no desenvolvimento de políticas públicas com reflex no currículo escolar. 


\section{AGRADECIMENTOS}

Os autores agradecem à Universidade Federal de Sergipe pelo apoio logístico, aos diretores e professores das escolas municipais, por facilitarem o acesso aos estudantes, aos adolescentes, por aceitarem participar e compartilhar suas ideias.

\section{REFERÊNCIAS BIBLIOGRÁFICAS}

1. Scott P, Lewis L, Quadros MT. Gênero, diversidade e desigualdades na educação: interpretações e reflexões para formação docente. Recife (PE): Editora Universitária UFPE; 2009. 202 p.

2. Moraes SP, Brêtas JRS, Vitalle MSS. Educação escolar, sexualidade e adolescência: uma revisão sistemática. J Heal Sci. 2018;20(3):221-30, doi: 10.17921/2447-8938.2018v20n3p221-230

3. Vieira KFL, da Nóbrega RPM, Arruda MVS, Veiga PMM. Representação social das relações sexuais: um estudo transgeracional entre mulheres. Psicol Ciência e Profissão. 2016;36(2):329-40, doi: 10.1590/1982-3703001752013

4. Assis SG, Gomes R, Pires TO. Adolescência, comportamento sexual e fatores de risco à saúde. Rev Saude Publica. 2014;48(1):43-51, doi: 10.1590/S0034-8910.2014048004638

5. Louro GL. Gênero, sexualidade e educação: das afinidades políticas às tensões teórico-metodológicas. Educ em Rev. 2007;46:201-18.

6. Castro MG. Violências, juventudes e educação: notas sobre o estado do conhecimento. Rev Brailseira Estud Popul. 2002;19(1):5-28.

7. Furlani J. Educação sexual na sala de aula - Relações de gênero, orientação sexual e igualdade étnicoracial numa proposta de respeito às diferenças. Belo Horizonte (MG): Autêntica; 2011. 192 p.

8. Santos AD, Campos MPA, Santos AMD. Sexualidade na adolescência: entre o desejo e o medo. Sci Plena. 2012;8(9):1-9.

9. Bezerra EO, Pereira MLD, Chaves ACP, Monteiro PV. Representações sociais de adolescentes acerca da relação sexual e do uso do preservativo. Rev Gaucha Enferm. 2015;36(1):84-91, doi: 10.1590/19831447.2015.01.45639

10. Altmann H. Orientação sexual nos parâmetros curriculares nacionais. Rev Estud Fem. 2001;9(2):575-85, doi: 10.1590/s0104-026x2001000200014

11. Santos BRL, de Souza ML. Novos olhares sobre gênero e sexualidade: transformações advindas de um curso de formação docente. Retratos da Esc. 2020;14(28):159-76, doi: 10.22420/rde.v14i28.1105

12. Louro GL. Gênero, sexualidade e educação - uma perspectiva pós-estruturalista. 6 ed. Petrópolis (RJ): Vozes; 1997. $179 \mathrm{p}$.

13. Louro GL, Neckel JF, Goellner SV. Corpo, gênero e sexualidade: discussões. Petrópolis (RJ): Vozes; 2003. $191 \mathrm{p}$.

14. Reis N, Pinho R. Gêneros não-binários: identidades, expressões e educação. Reflexão e Ação. 2016;24(1):7-25, doi: 10.17058/rea.v24i1.7045

15. Petry AR, Meyer DEE. Transexualidade e heteronormatividade: algumas questões para a pesquisa. Textos Context. 2011;10(1):193-8.

16. Torres CA, Beserra EP, Barroso MGT. Relações de gênero e vulnerabilidade às doenças sexualmente transmissíveis: percepções sobre a sexualidade dos adolescentes. Esc Anna Nery. 2007;11(2):296-302, doi: 10.1590/s1414-81452007000200017

17. Guimarães JS. "As meninas hoje tão muito soltas": os discursos institucionais que fundamentam o processo de regulação moral. Pro-Posições. 2019;30:1-25, doi: 10.1590/1980-6248-2017-0105

18. Lima JS, Landim MF. Meninos e meninas - um estudo sobre iniciação sexual com jovens do ensino fundamental. In: III Colóquio Internacional Educação e Contemporaneidade;22-24 set 2009; Itabaiana, SE, Brasil. [place unknown: publisher unknown]; 2009. 16 p.

19. Louro G. Heteronormatividade e Homofobia. In: Junqueira RD, editor. Diversidade sexual na educação: problematizações sobre a homofobia nas escolas. Brasília (DF): UNESCO; 2009. p. 85-93.

20. Meyer DE. Gênero e educação: teoria e política. In: Louro GL, Neckel JF, Goellner SV, editores. Corpo, gênero e sexualidade: um debate contemporâneo na educação. 9 ed. Petrópolis (RJ): Vozes; 2011. p. 5176.

21. Louro GL, Neckel JF, Goellner SV. Corpo, gênero e sexualidade: um debate contemporâneo na educação. 9 ed. Petrópolis (RJ): Vozes; 2011. 191 p.

22. Furlani J. Educação sexual: possibilidades didáticas. In: Louro GL, Neckel JF, Goellner SV, editores. Corpo, gênero e sexualidade: um debate contemporâneo na educação. 9 ed. Petrópolis (RJ): Vozes; 2011. p. 66-81. 
23. Meyer DE. Teorias e políticas de gênero: fragmentos históricos e desafios atuais. Rev Bras Enferm. 2004;57(1):13-8, doi: 10.1590/s0034-71672004000100003

24. Meyer DEE. Corpo, violência e educação: uma abordagem de gênero. In: Junqueira RD, editor. Diversidade sexual na educação: problematizações sobre a homofobia nas escolas. Brasília (DF): UNESCO; 2009. p. 213-35.

25. Jodelet D. Représentations sociales: un domaine en expansion. In: Jodelet D, editor. Les représentations sociales. Paris: PUF; 2003. p. 45-78, doi: 10.3917/puf.jodel.2003.01.0045

26. Moscovici S. Representações sociais: investigações em psicologia social. 7 ed. Petrópolis (RJ): Vozes; 2010. $408 \mathrm{p}$.

27. Carvalho JGS, Arruda A. Teoria das representações sociais e história: um diálogo necessário. Paid (Ribeirão Preto). 2008;18(41):445-56, doi: 10.1590/s0103-863x2008000300003

28. Wachelke JFR, Camargo BV. Representações sociais, representações individuais e comportamento. Rev Interam Psicol. 2007;41(3):379-90.

29. Furlani J. Mitos e tabus da sexualidade humana: subsídios ao trabalho em educação sexual. 3 ed. Belo Horizonte (MG): Autêntica; 2009. 196 p.

30. Gomes A, Nunes C. Representação Social do sexo nos jovens adultos portugueses. Psicol Reflex e Crit. 2015;28(1):177-85, doi: 10.1590/1678-7153.201528119

31. Góis ARS, dos Santos CNS, da Silva JC Filho, Garcia EGC, de Oliveira RC, Abrão FMS. Representações sociais de profissionais do sexo homossexuais, travestis e mulheres transexuais sobre a Síndrome da Imunodeficiência Adquirida. Enfermería Actual en Costa Rica. 2019;18(38):1-15, doi: 10.15517/revenf.v0i38.38533

32. Couto PLS, Paiva MS, Gomes AMT, Sorte ETB, Rodrigues LSA, Coelho EA. Significados a respeito da prevenção ao HIV/aids e da sexualidade para jovens católicos. Rev Gauch Enferm. 2017;38(4):e2016-80, doi: 10.1590/1983-1447.2017.04.2016-0080

33. Queiroz MAC, Lourenço RME, Coelho MMF, Miranda KCL, Barbosa RGB, Bezerra STF. Representações sociais da sexualidade entre idosos. Rev Bras Enferm. 2015;68(4):662-7, doi: 10.1590/0034-7167.2015680413i

34. Tejada DMG, Hernández EBR, López TMT, Martínez SLM. Te quiero... para una vez. Representaciones sociales del "sexo sin compromiso" en jóvenes mexicanos. Sex Salud y Soc. 2018;28:116-35, doi: 10.1590/1984-6487.sess.2018.28.07.a

35. Longaray DA. A importância da escola no combate ao preconceito. Divers e Educ. 2014;2(4):14-9.

36. Covas FSN. A proibição das aborgagens de gênero nas escolas. In: Direito e Diversidade. MPSP. São Paulo (SP): Ministério Público do Estado de São Paulo; 2018. p. 11-20.

37. Viza B-H, Santori MC, Zanello V. Maria da Penha vai à escola: educar para prevenir e coibir a violência doméstica e familiar contra a mulher. Brasília (DF): Tribunal de Justiça do Distrito Federal e dos Territórios; 2017. $210 \mathrm{p}$.

38. IBGE: Instituto Brasileiro de Geografia e Estatística. @Cidades - Itabaiana/SE [Internet]; c2017 [citado em 22 out 2020]. Disponível em: https://cidades.ibge.gov.br/brasil/se/itabaiana/panorama

39. Gomes MRO, Vieira N. Saúde e prevenção nas escolas: promovendo a educação em sexualidade no Brasil. Rev Tempus Actas em Saúde Coletiva. 2010;1:145-57.

40. Brasil. Caderno do Gestor do PSE. 1st ed. Brasília (DF): Ministério da Saúde; 2015. 68 p.

41. Minayo MCS. Análise qualitativa: teoria, passos e fidedignidade. Cienc e Saude Coletiva. 2012;17(3):621-6, doi: 10.1590/S1413-81232012000300007

42. Brasil. Ministério da Saúde, Conselho Nacional de Saúde. Resolução no 466, de 12 de dezembro de 2012. Dispõe sobre as normas e definições para realização de pesquisa envolvendo seres humanos. Diário Oficial da União. 13 jun 2013;12(Seção 1):59.

43. Nóbrega SM, Coutinho MPL. O teste de associação livre de palavras. In: Coutinho MPL, editor. Representações sociais: abordagem interdisciplinar. João Pessoa (PB): Editora Universitária UFPB; 2003. p. 67-77.

44. Moscovici S. Representações sociais: investigações em psicologia social. 11th ed. Petrópolis (RJ): Vozes; 2015. $408 \mathrm{p}$.

45. Greenacre M. Correspondence Analysis in practice. 2nd ed. Boca Raton (US): Chapman and Hall/CRC; 2007. 296 p. doi: $10.1201 / 9781420011234$

46. Kassambara A. Practical guide to Principal Component Methods in R. Estados Unidos: STHDA; 2017. $264 \mathrm{p}$.

47. Silva SMDT, Ferreira MMSV, Amaral-Bastos MM, Monteiro MAJ, Couto GR. Diagnóstico do conhecimento dos adolescentes sobre sexualidade. Acta Paul Enferm. 2020;33:1-7, doi: 10.37689/actaape/2020ao0210

48. IBGE: Instituto Brasileiro de Geografia e Estatística. Censo: Amostra - Religião [Internet]; [2011] [citado em 10 out 2020]. Disponível em: https://cidades.ibge.gov.br/brasil/pesquisa/23/22107 
49. Costa V, Fernandes SCS. O que pensam os adolescentes sobre o amor e o sexo? Um estudo na perspectiva das representações sociais. Psicol e Soc. 2012;24(2):391-401, doi: 10.1590/S0102-71822012000200017

50. Castro MG, Abramovay M, Silva LBS. Juventude e sexualidade. Brasília (DF): UNESCO Brasil; 2004. $426 \mathrm{p}$.

51. Amaral MA, Fonseca RMGS. Entre o desejo e o medo: as representações sociais das adolescentes acerca da iniciação sexual. Rev Esc Enferm USP. 2006;40(4):469-76, doi: 10.1590/s0080-62342006000400004

52. Oliveira DC, Tosoli AM, Corrêa S, Aparecida M. "Pegar", "ficar" e "namorar": representações sociais de relacionamentos entre adolescentes. Rev Bras Enferm. 2007;60(5):497-502.

53. Machado MDC. Representacões e relações de gênero nos grupos pentecostais. Rev Estud Fem. 2005;13(2):387-96.

54. Furlani J. Mulheres só fazem amor com homens? A educação sexual e os relacionamentos entre pessoas do mesmo sexo. Pro-Posições. 2008;19(2):111-31, doi: 10.1590/s0103-73072008000200009

55. Barreto MMM, Gomes AMT, Oliveira DC, Marques SC, Peres EM. Representação social da gravidez na adolescência para adolescentes grávidas. Rev Rene. 2011;12(2):384-92.

56. Aquino EML, Heilborn ML, Knauth D, Bozon M, Almeida MC, Araújo J, et al. Adolescência e reprodução no Brasil: a heterogeneidade dos perfis sociais. Cad Saúde Pública. 2003;19(Supl 2):377-88, doi: 10.1590/S0102-311X2003000800019

57. Peres SO, Heilborn ML. Cogitação e prática do aborto entre jovens em contexto de interdição legal: o avesso da gravidez na adolescência. Cad Saúde Pública. 2006;22(7):1411-20, doi: 10.1590/S0102311 X2006000700006

58. Perucchi J, Beirão AM. Novos arranjos familiares: paternidade, parentalidade e relações de gênero sob o olhar de mulheres chefes de família. Psicol Clínica. 2007;19(2):57-69, doi: 10.1590/s010356652007000200005

59. Cavenaghi S, Alves JED. Mulheres chefes de famílias no Brasil: avanços e desafios. Rio de Janeiro (RJ): ENS-CPES; 2018. 120 p.

60. Oliveira DC, Gomes AMT, Pontes APM, Salgado LPP. Atitudes, sentimentos e imagens na representação social da sexualidade entre adolescentes. Esc Anna Nery Rev Enferm. 2009;13(4):817-23, doi: 10.1590/s1414-81452009000400018

61. Santos JVO, Araújo LF, Castro JLF, Faro A. Análise prototípicea das representações sociais sobre as infecções sexualmente transmissíveis entre adolescentes. Psicogente. 2019;22(41):1-18, doi: 10.17081/psico.22.41.3312

62. Santos S. Profissionais de saúde frente ao aborto legal no Brasil: desafios, conflitos e significados. Cad Saúde Pública. 2003;19(2):399-406.

63. Matos M, Machado C, Caridade S, Silva MJ. Prevenção da violência nas relações de namoro: intervenção com jovens em contexto escolar. Psicol Teor e Prática. 2006;8(1):55-75.

64. Murta SG, Ramos CEPL, Cangussú EDA, Tavares TNG, da Costa MSF. Desenvolvimento de um website para prevenção à violência no namoro, abandono de relações íntimas abusivas e apoio aos pares. Context Clínicos. 2014;7(2):118-32, doi: 10.4013/ctc.2014.72.01

65. Mortari CLH, Martini JG, Vargas MA. Representações de enfermeiras sobre o cuidado com mulheres em situação de aborto inseguro. Rev da Esc Enferm da USP. 2012;46(4):914-21, doi: 10.1590/s008062342012000400019

66. Calile O. A homossexualidade e as representações sociais. BAGOAS. 2019;20:19-43.

67. Scardua A, Souza EA Filho. O debate sobre a homossexualidade mediado por representações sociais: perspectivas homossexuais e heterossexuais. Psicol Reflex e Crit. 2006;19(3):482-90, doi: 10.1590/s0102-79722006000300017

68. Pereira CR, Torres ARR, Pereira A, Falcão LC. Preconceito contra homossexuais e representações sociais da homossexualidade em seminaristas católicos e evangélicos. Psicol Teor e Pesqui. 2011;27(1):73-82, doi: 10.1590/S0102-37722011000100010

69. Brasil. Brasil Sem Homofobia. Programa de Combate à Violência e à Discriminação contra GLTB e de Promoção da Cidadania Homossexual. Brasília (DF): Ministério da Saúde; 2004. 31 p.

70. Rodrigues JRB, Silva JMM. Democracia e diferença em tramas político-curriculares contemporâneas: o Escola Sem Homofobia em análise. Educ em Rev. 2020;36:1-22, doi: 10.1590/0104-4060.75686 